\title{
Análise do planejamento e controle da produção sob a ótica da Teoria da Complexidade
}

\author{
Fernando Augusto Ferreira Dutra \\ Rolf Hermann Erdmann \\ UFSC
}

\begin{abstract}
Resumo
Neste trabalho buscou-se analisar o sistema de planejamento e controle da produção (PCP) das empresas a partir dos preceitos da Teoria da Complexidade. Esta Teoria sugere que as organizações e seus sistemas sejam vistos como sistemas complexos adaptativos [SCAs], sistemas cuja propriedade básica é a capacidade de ajustar seu comportamento em função das alterações ambientais. Um estudo de caso foi aplicado a duas empresas, no intuito de evidenciar aspectos típicos de SCAs presentes nos sistemas de PCP das mesmas. Os resultados evidenciaram que as implicações da Complexidade estão presentes na rotina de trabalho do PCP das empresas, sendo que foi possível identificar casos em que os preceitos da Teoria contribuíram na solução de problemas emergentes na rotina do PCP. No entanto, estas características podem ser mais desenvolvidas para que o sistema possa responder mais ativamente às alterações que acontecem em seu meio.
\end{abstract}

Palavras-chave

Sistemas de produção, PCP, Teoria da Complexidade.

\section{Analysys of the production planning and control under the view of the Complexity Theory}

\begin{abstract}
In this work the production planning and control [PPC] system of the organizations is analyzed under the concepts of the Complexity Theory. This theory suggests that the systems must be observed as complex adaptive systems (CASs). These kinds of systems have as basic property the ability to adjust their behavior to deal with new situations on their environment. A case study was applied to two organizations, looking forward to identify typical aspects of CASs on the PPC systems of the organizations. The results showed that the Complexity Theory implications are present in the routines of production planning and control of the organizations It was possible to identify situations where the Complexity aspects helped to solve problems on the PPC. However, the Complexity aspects can be more developed on the PPC systems. In this way, these systems can answer faster the changes that happen on their environment.
\end{abstract}

Key words

Production systems, PPC, Complexity Theory. 


\section{INTRODUC̣̃̃O}

As últimas décadas evidenciaram que novas tecnologias estão transformando produtos, processos, mercados e indústrias inteiras, revolucionando, desta maneira, o ambiente empresarial. Para Drucker (1996), a era do conhecimento, marcada por grandes organizações que operam com base no fluxo de informações, iniciou-se a partir das transformações mundiais ocorridas no final da década de 1960. Pode-se dizer que, nos dias atuais, um dos principais desafios das organizações é o de se adaptar a este ambiente em que a velocidade de mudança é muito grande.

$\mathrm{Na}$ era do conhecimento, as organizações que continuam presas ao paradigma mecanicista têm dificuldade de acompanhar as mudanças do mercado, pois a produção e a disseminação das informações acontecem de maneira cada vez mais rápida (NOBREGA, 1996; SHENK, 1997). O modelo mecanicista tem sido a forma de pensar dominante desde o século XVII, quando as leis de Newton legitimaram o mecanicismo e validaram suas implicações, linearidade, monocausalidade, determinismo, reducionismo e imediatismo (TÔRRES, 2005). que está se revelando no mundo empresarial só sobrevivem se forem adaptativos, isto é, se aprenderem a mudar.

A Teoria da Complexidade afirma que os SCAs possuem um tipo de dinamismo que os torna capazes de responder ativamente ao que ocorre ao seu redor, fazendo-os qualitativamente diferentes de objetos estáticos (AGOSTINHO, 2003b). Estes sistemas apresentam uma característica peculiar: a capacidade de auto-organização.

Diante deste cenário, de intensa competitividade e mudança intensa, no qual as organizações do mundo inteiro estão imersas, a função produção assume um importante papel junto ao objetivo geral das organizações, uma vez que atua como apoio, como implementadora e como impulsionadora da estratégia organizacional (SLACK et al., 1997).

De maneira geral, as atividades relativas à administração da produção tiveram sempre um foco prescritivo, sendo que essas atividades eram vistas como sendo fechadas ao ambiente em que se encontram. Percebe-se que a função produção precisa ser analisada como um sistema aberto ao seu ambiente de operação, sendo, assim, capaz de responder ativamente às mudanças.

O planejamento e controle da produção (PCP) representa o eixo operacional de uma organização. É consoante a esta atividade que se constrói a estratégia. Sua eventual deficiência projeta-se de forma imediata na qualidade do bem ou serviço produzido, na falta de confiabilidade de informações, em um pior aproveitamento dos recursos de produção, no descumprimento de prazos, no gerenciamento dos insumos, dentre outros aspectos. Os conceitos de eficiência e eficácia estão ligados a esta atividade.

Assim como as demais atividades referentes à adminis-

Este paradigma já não é mais suficiente para explicar os acontecimentos, pois isola as partes do fenômeno para analisá-las, considerando o todo como simples agregado das diversas partes. Os problemas de hoje são interligados, não havendo mais a possibilidade de soluções isoladas; apenas soluções sistêmicas parecem funcionar. Quando se caminha do simples para o complexo, o paradigma mecanicista mostra-se ineficiente na solução dos problemas organizacionais. Agostinho (2003b) corrobora ao afirmar que o mecanicismo e seus descendentes não conseguem dar conta do grau de incerteza e de fluidez que a economia e a sociedade vivem hoje. Desta maneira, as organizações de hoje só evoluem se aprenderem a funcionar como sistemas que trazem em sua estrutura a própria mudança (NOBREGA, 1996).

Uma das possibilidades de compreender a realidade fora do modelo mecanicista, apresentada pela Teoria da Complexidade, sugere que os sistemas sejam vistos como sendo sistemas complexos adaptativos (SCAs). Nobrega (1996) afirma que sistemas que atingem o grau de complexidade tração da produção, o PCP foi por muito tempo visto como uma atividade fechada ao seu ambiente de operação. Hoje percebe-se que o PCP é sensível aos acontecimentos ocorridos em seu ambiente externo. Sendo assim, vislumbrá-lo como um SCA contribui para que organizações dos mais diferentes setores possam obter insights significativos na condução de suas operações de produção.

Perante o exposto até o momento, surge o problema de pesquisa para o presente trabalho: verificar como as empresas vêm tratando as não-linearidades emergentes em seu PCP. Não-linearidades são definidas aqui como atividades ou situações que não estavam presentes na rotina de trabalho e que, quando emergem, forçam os trabalhadores a buscar uma solução.

Os resultados obtidos evidenciam que as implicações da Teoria da Complexidade se fazem presentes na rotina de trabalho do PCP das empresas, ao se verificar a presença de aspectos característicos de SCAs no sistema de PCP das mesmas. No entanto, deve-se ressaltar que esses mesmos 
aspectos podem ser mais desenvolvidos para que o sistema possa responder mais ativamente às alterações que acontecem em seu meio.

O próximo item apresenta uma síntese teórica desenvolvida a partir dos pilares que sustentaram a pesquisa, o PCP e a Teoria da Complexidade. Em seguida, descreve-se o método de pesquisa utilizado e, por fim, apresentam-se os principais resultados obtidos, bem como algumas considerações finais.

\section{O PCP SOB A ÓTICA DA TEORIA DA COMPLEXIDADE}

Um sistema de produção é uma das partes integrantes de uma organização, ao lado de outras, como vendas, marketing e gestão de pessoal. O sistema de produção, por sua vez, é composto por subsistemas, dentre eles o subsistema de PCP.

As definições encontradas na literatura (MONKS, 1987; MOREIRA, 1996; SLACK et al, 1997; CORRÊA et al., 1999; ERDMANN, 2000), de forma geral, definem o PCP como sendo um sistema de apoio à produção, que comanda e coordena o processo produtivo, objetivando cumprir o planejamento e a programação dos processos de maneira eficaz, para satisfazer os requisitos de tempo, qualidade e quantidades do sistema.

Seguindo a interpretação de Erdmann (2000) para o PCP, observa-se que ele pode ser dividido em duas etapas principais: o planejamento da produção, composto de procedimentos que preparam e organizam as informações que permitem a programação e o controle da produção; e a programação e o controle da produção, que estabelece antecipadamente as atividades da produção em médio e curto prazo e realiza o acompanhamento da produção, colhendo informações para subsidiar correções de eventuais desvios da programação.

Teoricamente, a administração da produção sugere as ações de maneira prescritiva, de acordo com o paradigma mecanicista. No entanto, verifica-se que as práticas de planejamento, programação e controle das operações já não representam a efetividade desejada. Nem sempre o que é planejado ou programado ocorre da maneira que foi prevista. A quantidade de relações, tanto internas quanto externas à organização, torna impossível saber os resultados de todas as interações e combinações possíveis (AGOSTINHO, 2003b).

Neste sentido, “[...] os limites de uma ação gerencial clássica tornam-se evidentes - dificuldade ou impossibilidade de planejamento e controle totais, limites cognitivos à racionalidade e mesmo o processo de complexificação do mundo" (AGOSTINHO, 2003a, p. 3). A partir daí surgiu a proposta de analisar o PCP sob a ótica de um novo paradigma, baseado na Teoria da Complexidade, para, assim, compreender como funciona o processo de autoorganização destes sistemas.

A Teoria da Complexidade surge diante da necessidade de uma nova concepção de ciência, fora do padrão mecanicista/newtoniano convencional, na busca do entendimento de como certas coisas - células, um bando de pássaros, cidades, civilizações, organizações - conseguem manter uma coerência em situações de contínua mudança, sem que haja um planejamento central (NOBREGA, 1996).

É uma ciência que estuda as propriedades emergentes, ou seja, propriedades que surgem da interconexão dos elementos de um sistema, e que surgem num certo nível de relação, não existindo nos níveis inferiores. Desta maneira, uma vez que certas condições estejam presentes, a ordem pode surgir de situações aparentemente caóticas (AGOSTINHO, 2003b).

Segundo Morin (1977), os sistemas vivem em constante oscilação dentro do anel tetralógico de ordem/desordem/interação/organização. Sendo assim, a partir de um momento de desordem, os indivíduos, por intermédio das interações, provocam uma nova ordem da organização, e assim sucessivamente. Os conceitos de ordem e de organização só se desenvolvem em função um do outro. Quanto mais a ordem e a organização se desenvolvem, mais se tornam complexas, mais toleram, utilizam e necessitam da desordem. Desta maneira, a organização é o resultado das interações dinâmicas da desordem com os acomodamentos estáticos da ordem (MORIN, 1977).

Conforme afirma Klement (p. 6, 2000), “ordem, desordem e organização não são lineares, nem mutuamente excludentes. Estas noções interagem dialogicamente, isto é, relativizam-se continuamente, mantendo o sistema em atividade". Assim sendo, evidencia-se que os SCAs existem na dialógica entre a ordem e a desordem (LEITE et al., 2004).

O termo SCA foi cunhado diante da percepção de que certos tipos de sistemas são capazes de responder ativamente aos acontecimentos ao seu redor. Agostinho (2003b) identifica a adaptação como sendo a propriedade básica dos SCAs, no sentido de que o sistema é capaz de ajustar seu comportamento a partir do que consegue perceber sobre as condições do seu meio ambiente e sobre seu desempenho. Nobrega (1996) afirma que os sistemas complexos aprendem, auto-organizam-se e evoluem através da habilidade de processar a informação que chega de fora.

Tomando por base o funcionamento dos SCAs, Agostinho (2003b) elege quatro conceitos-chave que definem a abordagem dos sistemas vistos como sendo complexos adaptativos: autonomia, cooperação, agregação e auto-organização. São conceitos fortemente entrelaçados que indicam como a ordem no sistema pode emergir através das ações de suas partes. Esses conceitos se relacionam da seguinte maneira (AGOSTINHO, 2003b, p. 36): 
Indivíduos autônomos, capazes de aprender e de se adaptar, cooperam entre si obtendo vantagens adaptativas. Tal comportamento tende a ser selecionado e reproduzido, chegando ao ponto em que estes indivíduos cooperativos se unem formando um agregado que também passa a comportar-se como um indivíduo e assim por diante. Diz-se, então, que o sistema resultante se auto-organiza, fazendo emergir um comportamento global cujo desempenho também é avaliado por pressões de seleção presentes no ambiente (externo e interno).

Agostinho (2003b) ressalta também a importância da existência de pontos de alavancagem, ou seja, pontos em que uma ação pode gerar efeito amplificador. Assim, é esperado que se possa influenciar o comportamento de um SCA através de ações dirigidas a certos pontos de alavancagem, gerenciando, assim, o processo de auto-organização do sistema.

Uma das características principais de um SCA é o fato de ser um sistema aberto. Stacey (1991) argumenta que sistemas abertos necessitam de uma forma de aprendizagem diferente daquelas encontradas em sistemas fechados, e que o caos e a instabilidade dentro dos sistemas podem colaborar no desenvolvimento de insights na resolução dos problemas. Smith e Eliot (1999) afirmam que uma das barreiras à frente da aprendizagem é a tendência do sistema de focar o aprendizado no circuito simples ao invés do circuito duplo.

A aprendizagem em circuito simples apóia-se numa habilidade de detectar e corrigir o erro com relação a um dado conjunto de normas operacionais. As estratégias são definidas de acordo com o modelo mental do sistema, não se criando desta maneira inovação, uma vez que apenas se repetem práticas consideradas adequadas (MORGAN, 1996). Assim, o conhecimento obtido com a experiência é reproduzido pelo agente e por aqueles que aderem à experiência (STACEY, 1998, apud REBELO, 2004).

A saída é a utilização de outra forma de aprender que conduz à inovação daquilo que está sendo sistematicamente praticado (REBELO, 2004). A aprendizagem em circuito duplo depende da capacidade de olhar-se duplamente a situação, questionando a relevância das normas de funcionamento e das variáveis do modelo vigente, ocorrendo assim um processo de reflexão sobre a alteração do modelo mental que impele o primeiro circuito (MORGAN, 1996).

Stacey (1998, apud REBELO, 2004) adverte que a aprendizagem em circuito simples é apropriada para lidar com situações previsíveis bem definidas, mas é necessária a aprendizagem em circuito duplo nas situações ambíguas e imprevisíveis das quais emergem as inovações.

Assim, pode-se sumarizar que um SCA interage com seu ambiente, aprendendo e evoluindo com a experiência, e, desta maneira, adapta-se às novas situações que surgem em seu ambiente. Podem-se enumerar como características comuns aos SCAs:

- Complexidade vs. Simplicidade - apesar de ser um sistema globalmente complexo, é um sistema que apresenta simplicidade local.

- Grande número de componentes que interagem entre si e influenciam uns aos outros - ou seja, são integrados por elevado número de componentes que interagem entre si.

- Não conseguem ser analisados pelos métodos científicos lineares de causa e efeito. O método reducionista de análise não é utilizável para o estudo e previsão desses sistemas.

- Sempre há aspectos aleatórios envolvidos, ou seja, não são, de forma alguma, sistemas determinísticos ou previsíveis.

- Ampla diversidade de componentes que se inter-relacionam e que mantêm similaridades dentro da diversidade.

- São capazes de evoluir, se adaptar e aprender de acordo com mudanças nas características de seu ambiente.

- Não há uma coordenação global, efetiva e duradoura, apesar de que vários mecanismos de coordenação menos rígidos possam estar presentes.

Perante o exposto até o momento, verifica-se que o PCP pode ser visto como sendo um SCA por uma série de razões principais, aqui enumeradas:

- É um sistema, uma vez que é um agrupamento de partes que operam juntas, buscando atingir um objetivo comum;

- É um sistema dinâmico, pois o tempo é uma variável do sistema;

- É um sistema aberto, visto que se relaciona o tempo todo com o ambiente externo;

- É um sistema não-linear, uma vez que as relações de causa e efeito não são sempre correspondentes;

- É um sistema complexo, já que novas propriedades emergem pela inter-relação entre os componentes do sistema;

- É um sistema adaptativo, pois as partes mudam para se adaptar a estímulos internos e externos.

\section{O MÉTODO UTILIZADO NO TRABALHO}

O problema de pesquisa que norteou este trabalho consiste em verificar como as empresas vêm tratando as não-linearidades emergentes em seu PCP. Assim sendo, buscou-se identificar como os conceitos-chave dos SCAs se fazem presentes no modo de condução do sistema de PCP, colaborando no sentido de superar as não-linearidades sempre presentes na rotina de trabalho. 
Para atingir-se o objetivo proposto, um estudo de caso foi elaborado e aplicado a duas empresas pertencentes a setores industriais diferentes. Segundo Godoy (1995), este modo de investigação é o mais adequado quando o pesquisador deseja responder às questões "como" e "por que" e quando o foco de interesse é acerca de fenômenos atuais, isto é, que só poderão ser analisados dentro de um contexto de vida real.

Voss et al. (2002) afirmam que o gerenciamento da produção, de maneira geral, é uma área muito dinâmica, onde novas práticas emergem continuamente, e que o estudo de caso é o modo propício de se estudar essas práticas emergentes, além de ser um instrumento propício para o desenvolvimento de novas teorias em gerenciamento da produção.

Vale ressaltar ainda que a Teoria da Complexidade é uma ciência relativamente nova, ainda em processo de formulação e, por isso, pesquisas com resultados concretos sobre a Teoria reforçam as bases de sustentação da mesma.

Assim, buscou-se identificar aspectos típicos de SCAs na prática do PCP destas empresas, bem como situações em que não-linearidades emergentes no PCP foram solucionadas, de acordo com os preceitos da Teoria da Complexidade, e estas soluções, incorporadas à prática do PCP. A análise desenvolvida possibilita que empresas de setores distintos façam inferências acerca de seus próprios sistemas de PCP, baseando-se nos resultados obtidos na pesquisa.

Os dados foram obtidos através de entrevistas semi-estruturadas a pela observação não-participante. Foram entrevistadas pessoas diretamente envolvidas com o PCP e de diferentes níveis hierárquicos dentro da empresa. Para conduzir a pesquisa, um protocolo de estudo de caso foi elaborado, uma vez que é um instrumento essencial para aumentar a confiabilidade da pesquisa e fundamental ao pesquisador para a condução da mesma (YIN, 2001).

O protocolo utilizado neste trabalho segue a modelagem sugerida por Yin (2001), podendo ser dividido em três partes principais: os procedimentos de campo, as questões do estudo de caso e as fontes de evidências.

Os procedimentos de campo referem-se ao processo pelo qual as empresas da amostra foram selecionadas, ao contato inicial com essas empresas e ao roteiro básico de pesquisa.

O ponto central do protocolo foi um conjunto de questões utilizadas nas entrevistas semi-estruturadas. Estas questões foram elaboradas com o intuito de identificar as características de SCAs nos sistemas analisados: autonomia, cooperação, agregação, auto-organização e circuito duplo de aprendizado.

Como fontes de evidências foram utilizadas entrevistas com funcionários das empresas, observação direta no chão de fábrica e escritórios, bem como documentos disponibilizados pela empresa.
De posse dos dados, foi realizada a análise dos mesmos, fundamentada no anel tetralógico de Morin (1977). A Figura 1 apresenta o esquema utilizado para realizar-se a análise dos dados. Buscou-se compreender de que maneira os conceitos-chave dos SCAs estão presentes na organização do sistema frente às não-linearidades, num esforço de retorno da desordem para a ordem. Para tanto, procurou-se identificar nos sistemas estudados as características dos conceitos-chave definidos:

- Autonomia: pode ser verificada pela existência de canais de participação e pelo tipo de influência permitido. $\mathrm{Na}$ análise do sistema, buscar identificar as vantagens referentes à autonomia: adaptabilidade, aumento da diversidade, aprendizado, redução de erros e solução de conflitos.

- Cooperação: pode ser verificada pela existência de mecanismos que estimulem o encontro entre as pessoas e a existência do espírito de equipe, propiciando assim a facilidade de acesso às informações, a existência de oportunidades de crescimento, a interação com o ambiente externo, a expansão dos limites da empresa e para além da empresa.

\section{A s práticas de planejamento, - programação e controle das operações já não representam a efetividade desejada}

- Agregação: pode ser verificada pela existência de redes colaborativas, onde as ações dos grupos são interdependentes, na busca de se atingir um objetivo comum, propiciando assim a sedimentação da aprendizagem e o surgimento das propriedades emergentes do sistema.

- Auto-organização: verificada pela existência de condições propícias para a emergência do potencial autoorganizante do sistema, condições essas advindas dos conceitos-chave anteriores, afastando-se assim da prescrição e do controle.

- Circuito duplo de aprendizado: verificado pela presença de situações em que o modelo organizacional que delineia o sistema é alterado, possibilitando o surgimento das inovações.

A ordem representa a estrutura e o funcionamento do PCP tal como foi projetado nas empresas, sendo necessário, desta maneira, compreender detalhadamente a estruturação do PCP da empresa analisada. A desordem reflete as múltiplas não-linearidades, em princípio imprevistas e indesejadas. São as perturbações do ambiente e as combinações decorrentes. Tem-se, assim, a oportunidade de entender ou então 
perceber as oportunidades para criar diferenciações internas, capazes de subsidiar a organização, que seria a reação a uma desordem, ou seja, é a retomada (ou tentativa) da situação original.

Quando a situação original não é alcançada ou não é visada, pode-se buscar um patamar novo de operação, podendo ser um estágio evoluído, capaz de proporcionar vantagem competitiva à organização. Assim, analisase também o processo de evolução do sistema a cada experimentação, conforme preconiza o circuito duplo de aprendizado. Para tanto, deve-se verificar se a aprendizagem advinda da resolução das não-linearidades emergentes no PCP é de fato incorporada ao sistema de PCP da empresa, conduzindo assim a um processo de adaptação contínua.

\section{CARACTERIZAC̣ÃO DO SISTEMA DE PCP DAS EMPRESAS ANALISADAS}

Na medida em que este trabalho trata do tema PCP, mostra-se necessário caracterizar o sistema de PCP utilizado pelas empresas analisadas. De acordo com a interpretação de Erdmann (2000), o PCP é dividido em duas partes. A primeira delas é o planejamento, responsável pelo projeto de produtos e processos e também pela definição de quantidades. A segunda parte é a programação e o controle da produção, responsável por estabelecer antecipadamente as atividades da produção e também por corrigir eventuais desvios de rota.

O Quadro 1 apresenta as características do PCP das empresas analisadas.

\section{ANÁLISE DO PCP VISTO COMO UM SISTEMA COMPLEXO ADAPTATIVO}

O trabalho proposto foi aplicado em duas empresas pertencentes a setores industriais diferentes. Uma das empresas pesquisadas, aqui denominada Empresa A, é um frigorífico de aves. A segunda empresa, aqui denominada Empresa B, é uma fabricante de telefones e de centrais telefônicas. Apresentam-se a seguir os aspectos típicos de SCAs identificados no modo de condução do PCP nas duas empresas.

Um dos elementos que vai legitimar a ação autônoma é a redução ou mesmo a eliminação dos símbolos de status. Alguns aspectos que podem parecer de menor importância são cruciais para promover a autonomia e a cooperação entre os empregados (AGOSTINHO, 2003b). A Empresa A caminha bem nesse sentido, uma vez que foi observado no escritório onde fica o pessoal responsável pelo PCP a ausência de divisórias. Os funcionários trabalham em um ambiente aberto, que permite a fácil comunicação entre as pessoas, sendo que em um mesmo ambiente trabalham pessoas de diferentes setores. Esse fato facilita a comunicação e dinamiza a solução de problemas, além de promover um ambiente agradável para se realizar o trabalho, uma vez que o "medo" da sala da diretoria é completamente eliminado.

Existem algumas situações que podem se tornar conflitantes devido às restrições para a tomada de uma decisão. Nessas situações, o potencial auto-organizante do sistema torna-se evidente.

Um caso que pôde ser observado na Empresa A, ainda que não consciente, foi o relato do processo de desenvolvimento de um novo produto. Esse processo envolve várias

Figura 1: Esquema de análise dos dados.

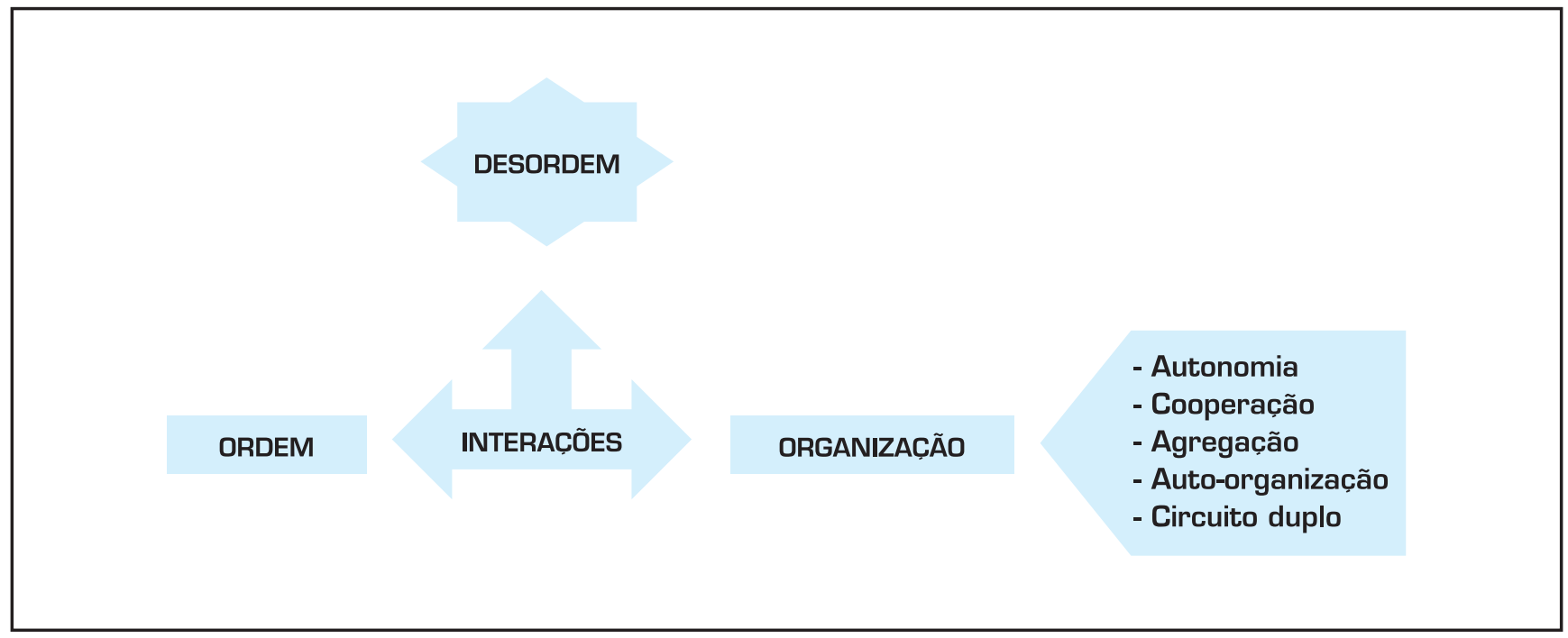

Fonte: Adaptado de Morin (1977) e Agostinho (2003b). 
Quadro 1: Caracterização do PCP das empresa analisadas.

\begin{tabular}{|c|c|c|c|}
\hline \multicolumn{2}{|c|}{ ETAPA DO PCP } & DESGRIÇÃO - EMPRESA A & DESCRIÇÃO - EMPRESA B \\
\hline \multirow[b]{3}{*}{$\begin{array}{l}\text { Planejamento da } \\
\text { Produção }\end{array}$} & $\begin{array}{l}\text { Projeto do } \\
\text { produto }\end{array}$ & $\begin{array}{l}\text { - Departamento de novos produtos } \\
\text { coordena o projeto, que envolve } \\
\text { todos os setores relativos à } \\
\text { produção. }\end{array}$ & $\begin{array}{l}\text { - Times de projeto. } \\
\text { - Novos produtos desenvolvidos } \\
\text { levando-se em conta as demandas } \\
\text { mercadológicas. }\end{array}$ \\
\hline & $\begin{array}{l}\text { Projeto do } \\
\text { processo }\end{array}$ & $\begin{array}{l}\text { - Intrinsecamente ligado ao projeto } \\
\text { do produto, seguindo os preceitos } \\
\text { da engenharia simultânea. }\end{array}$ & $\begin{array}{l}\text { - Intrinsecamente ligado ao projeto } \\
\text { do produto, seguindo os preceitos } \\
\text { da Engenharia Simultânea. }\end{array}$ \\
\hline & $\begin{array}{l}\text { Definição de } \\
\text { quantidades }\end{array}$ & $\begin{array}{l}\text { - PCP analisa a capacidade } \\
\text { produtiva para novos itens. } \\
\text { - Previsão de demanda é } \\
\text { responsabilidade do setor } \\
\text { comercial. } \\
\text { - Horizonte de planejamento de } 12 \\
\text { meses. } \\
\text { - Produção para um mês é baseada } \\
\text { na média para os três meses } \\
\text { anteriores. }\end{array}$ & $\begin{array}{l}\text { - Consolidação da previsão } \\
\text { da demanda realizada pelo } \\
\text { departamento de Marketing } \\
\text { através das análises dos gerentes } \\
\text { de vendas regionais. } \\
\text { - Utilização de ferramentas de } \\
\text { suporte à previsão da demanda } \\
\text { (CRM, BI, Banco de Dados). }\end{array}$ \\
\hline \multirow{5}{*}{$\begin{array}{l}\text { Programação } \\
\text { e Controle da } \\
\text { Produção }\end{array}$} & $\begin{array}{l}\text { Definição das } \\
\text { quantidades de } \\
\text { produtos finais }\end{array}$ & $\begin{array}{l}\text { - A partir dos planos anual e } \\
\text { mensal, realiza-se a programação } \\
\text { diária da produção. }\end{array}$ & $\begin{array}{l}\text { - O PMP, elaborado com os } \\
\text { dados da previsão de demanda, } \\
\text { contempla as necessidades } \\
\text { de matéria-prima, capacidade } \\
\text { produtiva e mão-de-obra para a } \\
\text { produção das quantidades finais. }\end{array}$ \\
\hline & $\begin{array}{l}\text { Cálculo das } \\
\text { necessidades de } \\
\text { materiais }\end{array}$ & $\begin{array}{l}\text { Quantificam-se as partes que } \\
\text { serão geradas com o desmonte } \\
\text { da matéria-prima. }\end{array}$ & $\begin{array}{l}\text { - MRP, alimentado pelo PMP, gera } \\
\text { as ordens de compra de matéria- } \\
\text { prima. }\end{array}$ \\
\hline & $\begin{array}{l}\text { Definição } \\
\text { de prazos } \\
\text { capacidades e } \\
\text { ajustes }\end{array}$ & $\begin{array}{l}\text { - Ajuste fino da produção é } \\
\text { realizado através das ordens de } \\
\text { produção diárias. }\end{array}$ & $\begin{array}{l}\text { - Ajuste fino realizado através das } \\
\text { ordens de montagens diárias, } \\
\text { para que se tenha o horizonte de } \\
\text { requisição de matéria-prima. }\end{array}$ \\
\hline & $\begin{array}{l}\text { Liberação de } \\
\text { ordens }\end{array}$ & $\begin{array}{l}\text { - Monitor de célula recebe ordem } \\
\text { que dispara a produção. } \\
\text { - Regra FIFO. }\end{array}$ & $\begin{array}{l}\text { - Depende do produto e da linha } \\
\text { de atuação, alguns itens são } \\
\text { produzidos apenas por pedido. } \\
\text { - Considera os pedidos confirmados } \\
\text { em carteira para realizar o } \\
\text { seqüenciamento. }\end{array}$ \\
\hline & Controle & $\begin{array}{l}\text { - Controle de quantidade: } \\
\text { desvios admissíveis e desvios } \\
\text { inadmissíveis. } \\
\text { - Controle de qualidade: inspeção } \\
\text { por amostragem. }\end{array}$ & $\begin{array}{l}\text { - Controle de quantidades: relatório } \\
\text { comparando o previsto e o } \\
\text { realizado é emitido diariamente; } \\
\text { quadros visuais ao longo da linha } \\
\text { de produção. } \\
\text { - Controle de qualidade: trabalha } \\
\text { com controle estatístico de } \\
\text { processo; vários pontos de teste } \\
\text { ao longo do processo. }\end{array}$ \\
\hline
\end{tabular}

Fonte: Autores, 2006. 
áreas da empresa, as quais vão procurar defender seu próprio interesse. O PCP vai analisar a possibilidade de produção, verificando o impacto em fatores tais como a capacidade da fábrica e a mão-de-obra disponível, a Produção de Aves vai analisar a capacidade de fornecimento da matéria-prima, enquanto o setor Comercial vai procurar atender a demanda do mercado.

Neste sentido, os indivíduos vão interagir movidos por regras locais, ou seja, os balizadores de seus respectivos setores, procurando defender seus interesses ou do agregado do qual fazem parte. Através dessa interação emerge uma solução satisfatória, no caso a decisão de produzir ou não o novo produto. Essa decisão não necessariamente agradará a todos os envolvidos no processo, porém será a melhor decisão para a organização como um todo. Aqui, o PCP exerce um papel de mediador, sendo que sua atuação fornece uma base para a interação entre os setores envolvidos na tomada de decisão. Através desse caso é possível perceber todo o potencial da auto-organização para a empresa. alavancagem, no caso, o ponto onde ocorreu um problema. $\mathrm{O}$ input no foco do problema vai produzir grandes e direcionadas mudanças, de maneira a corrigir o que não foi planejado e evitar que o mesmo problema aconteça no futuro.

Durante a pesquisa de campo percebeu-se também a existência do aprendizado em circuito duplo, para que o sistema seja capaz de aprender. Dentro do processo produtivo, ao confrontar o realizado com o programado, o PCP procura entender as discrepâncias, verificar onde ocorreu o erro e quais os motivos que levaram ao desvio, e não apenas corrigir o problema e retomar a rota original. Agindo desta maneira, novas experiências vão sendo incorporadas à prática do PCP, o que leva o sistema a um processo de evolução, de acordo com o aprendizado em circuito duplo.

O surgimento de aspectos típicos de SCAs nas práticas da Empresa B remonta ao início da década de noventa, quando a empresa passou por uma grande crise e decidiu que o downsizing seria a solução inicial mais viável para tentar lidar com a mesma. O quadro de empregados foi reduzido de 650 para 150 .

A empresa percebeu que o mercado globalizado exigia produtos em massa, porém com altos índices de qualidade e preço competitivo. Os colaboradores remanescentes iniciaram programas

Um outro exemplo que pode ser relatado é a melhoria de processos. Na Empresa A, se um empregado de chão de fábrica enxerga uma possível melhoria (autonomia), ele automaticamente a posiciona para seu supervisor direto (cooperação). Em seguida, todas as pessoas participantes no referido processo são envolvidas (agregação), para que se faça em conjunto uma análise do que foi proposto. Esse processo é realizado de maneira dinâmica e todos têm a liberdade de poder questionar, criticar e dar sugestões para que o processo seja melhorado (auto-organização). A Empresa A incentiva seus empregados a participar desse processo de melhoria e faz com que eles cultivem esta cultura.

Na Empresa A o PCP tem um papel fundamental no processo auto-organizante, conforme relata o gerente de planejamento:

O PCP tem a responsabilidade de mostrar, escancarar o problema, e buscar ações para que aquele problema seja resolvido. Mostrar para a organização onde mora o problema. Isso foi programado. Isso foi realizado. Aqui estão as diferenças. Isso não foi realizado. Devese buscar o responsável, que tem autoridade sobre o processo e cobrar ' $\mathrm{O}$ que você vai fazer para resolver esse problema'.

Percebe-se, pela fala do gerente de planejamento, um comportamento típico de um SCA, ao trabalhar um ponto de intensivos de treinamento, envolvendo aspectos de administração da qualidade total e Just-in-time, com a aplicação de técnicas destas filosofias, como kanban, melhoria contínua, círculos de controle da qualidade e $5 \mathrm{~S}$. $\mathrm{O}$ sistema produtivo da empresa também foi reorganizado, com a adoção das células de produção em grande parte da produção, proporcionando menores tempos de ajuste e maior flexibilidade.

Entretanto, a principal mudança foi de mentalidade. A gestão, antes centralizada e autoritária, do tipo "faça porque quem manda sou eu", foi completamente revista. Houve redução dos níveis hierárquicos e adoção de uma gestão mais participativa, focada nas pessoas, que formaram um agregado cujo objetivo fundamental era reverter a situação da empresa.

A empresa crê que cada colaborador é uma pessoa especial e que deve encontrar em seu ambiente de trabalho condições adequadas para se desenvolver, como profissional assim como pessoa. E é a partir dessa mudança de mentalidade que emergem os aspectos típicos de SCAs nas práticas da empresa, sendo que podem ser identificados vários princípios da gestão autônoma dentro dessas práticas.

Um dos princípios dos SCAs mais fortes na Empresa B é a autonomia. Esse princípio e as vantagens decorrentes são resultados da mudança do modelo de gestão autoritária, que marcou a empresa até a crise na década de noventa, para o modelo de gestão participativa. Os colaboradores, como são chamados os empregados da empresa, têm total liberdade 
para tomar decisões em sua área de atuação no processo produtivo.

O novo modelo de gestão diminuiu o número de níveis hierárquicos, levando a mais agilidade e eficácia. Isto legitimou a autonomia e trouxe vantagens, como adaptabilidade, aumento da diversidade e solução de conflitos.

A adaptabilidade é resultado direto da agilidade e eficácia advinda da redução dos níveis hierárquicos, primeiramente porque a redução do número de pessoas em cargos de comando reduz custos, diminuindo as atividades que não agregam valor ao produto. Em segundo lugar porque um número menor de pessoas envolvidas no processo aumenta a intensidade da relação entre elas (AGOSTINHO, 2003b). Esse fato pode ser observado na Empresa B, nas equipes responsáveis pelos processos de produção. A integração entre as pessoas é total, envolvendo colaboradores do PCP, dos setores de suprimento e expedição, do setor comercial e também dos operadores de chão-de-fábrica. Essa característica proporciona à empresa uma maior adaptabilidade às mudanças.

O aumento da diversidade é outra característica proporcionada pela autonomia. Na Empresa B é propiciado aos colaboradores um ambiente de trabalho que permite utilizar todo o seu potencial criativo, aumentando-se assim a probabilidade de geração de novas idéias (AGOSTINHO, 2003b).

Os colaboradores apresentam sugestões de melhorias para o processo com o qual trabalham. Estas sugestões emergem da própria rotina de trabalho, da troca de experiências com os pares e de sua própria base de conhecimento. As sugestões podem até não ser todas acatadas, mas todas são analisadas, pois a empresa valoriza as contribuições que vêm de todos os colaboradores.

O exemplo de uma idéia que veio de um ferramenteiro da empresa ilustra esta característica. Este colaborador sugeriu que fosse feita uma simples alteração em um veículo de transporte de palets, aumentando-se o tamanho do garfo. Esta sugestão foi analisada e em seguida acatada, proporcionando um aumento de $100 \%$ de capacidade de transporte do veículo. Apesar de ser uma idéia simples, nenhum engenheiro de produto ou de processo vislumbrou a oportunidade de melhoria.

Uma outra vantagem trazida pela autonomia é a solução local de conflitos, sem necessidade de que tal situação tome maior vulto. Segundo o gerente industrial entrevistado, essa prática é bastante disseminada. Se há problemas envolvendo um grupo de trabalho, os colaboradores têm total autonomia para parar e discutir com os colegas e com o supervisor da área, sem a necessidade de envolver outras pessoas.

As pessoas são encorajadas a falar e a escrever sugestões. Há um sistema de sugestões e reclamações envolvendo cartões. Qualquer problema que um colaborador tenha é co- municado ao seu supervisor e pode ser escrito em um cartão e pendurado em um painel, e quem o pendurou tem o direito de receber uma resposta ou uma solução efetiva. Se a solução envolver outros setores além da produção, o colaborador que sugeriu acompanha o supervisor em reuniões com outros setores, para que se encontre uma solução viável.

A maneira de olhar para o princípio da cooperação também sofreu grande alteração com a mudança do modelo de gestão. Com o modelo autoritário as pessoas desempenhavam suas funções porque assim lhes era ordenado fazer e, somente deste modo receberiam sua recompensa, o seu salário.

Com o novo modelo de gestão participativa e de valorização das pessoas, os colaboradores tomaram consciência de que sua recompensa vem com o bom desempenho da organização, e que esse é um bom motivo para cooperar. De acordo com a empresa, os colaboradores que ali estão acreditam na empresa e empenham o seu comprometimento e dedicação.

A política de valorização do colaborador que já está ali fortalece esse aspecto. A maior parte dos empregados da Empresa B foi desenvolvida ali mesmo e cresce com os valores da mesma sedimentados em sua maneira de trabalhar. Este aspecto fortalece ainda mais a organização, já que possibilita a formação de fortes agregados que trabalham buscando os melhores resultados possíveis para a organização.

Conforme afirma Agostinho (2003b, p.114), “o princípio da auto-organização estabelece que a direção da organização deve garantir que o resultado das ações seja reportado aos atores e que estes sejam capazes de compreendê-lo e de ajustarem seus comportamentos". Esse fundamento do princípio da auto-organização é atingido através de mecanismos eficientes de feedback.

A Empresa B tem mecanismos estabelecidos de feedback envolvendo tanto pessoas quanto processos. São vários os indicadores que avaliam a eficácia do processo produtivo. Um exemplo está no controle das quantidades produzidas. A empresa adotou a comunicação visual para mostrar aos colaboradores a existência de problemas no processo produtivo.

Quando as pessoas envolvidas no processo verificam que o planejado não foi cumprido no dia anterior, elas se agregam buscando compreender onde aconteceu o problema que impossibilitou o alcance da meta. Esse é um mecanismo que também potencializa a equipe, pois ao colocar certa pressão neste ponto de alavancagem, faz com que os colaboradores trabalhem melhor para evitar que o mesmo problema aconteça devido às mesmas causas.

No nível pessoal, a empresa realiza a denominada Avaliação $360^{\circ}$, em que o colaborador avalia os seus pares e superiores e é avaliado pelos seus subordinados. Este processo é sempre acompanhado pelo departamento de recursos hu- 
manos, que contribui para que o colaborador se desenvolva nos pontos que, eventualmente, forem considerados fracos em sua avaliação.

Segundo o gerente industrial da empresa, a mudança do modelo de gestão correspondeu a uma mudança de mentalidade dos que ali estavam e, para ele, a maior responsável pela virada da empresa diante da crise no início dos anos noventa foi "acreditar no potencial das pessoas que ficaram". Ainda conforme este gerente, a organização nunca está satisfeita com o patamar em que se encontra. Ela sempre acredita que pode melhorar ainda mais. Observa-se que todos na empresa concordam com esta postura. Desta forma, o contexto dessa mudança de modelo de gestão permitiu identificar várias características típicas de SCAs.

O Quadro 2 sintetiza as características de SCAs identificadas nas empresas analisadas.
Um evento não esperado ocorrido no processo de produção de uma empresa é sempre um complicador. Dependendo da maneira como a sistema produtivo da empresa está organizado, um problema em alguma das etapas do PCP pode ocasionar uma parada em todo o processo produtivo. Desta forma, o sistema deve procurar resolver os eventos não-lineares da maneira mais rápida possível e evitar sua repetição.

Neste contexto, e tomando por base as implicações da Teoria da Complexidade, observa-se que o PCP está fortemente sujeito às não-linearidades emergentes na rotina de trabalho. Puderam ser identificadas várias soluções adotadas pelas empresas para solucionar as não-linearidades emergentes no PCP das mesmas. Estas soluções são um reflexo das características de SCAs presentes no modo de operar das empresas e são apresentadas no Quadro 3.

\section{Quadro 2: Características de SCAs identificadas nas empresas analisadas.}

\begin{tabular}{|c|c|c|}
\hline CARAGTERÍSTICA & EMPRESA A & EMPRESA B \\
\hline Autonomia & $\begin{array}{l}\text { - Liberdade na tomada de decisões por parte } \\
\text { dos funcionários, desde que dentro de suas } \\
\text { alçadas de atuação. } \\
\text { - Redução de símbolos de status: ausência } \\
\text { de divisórias no escritório, funcionários de } \\
\text { diferentes níveis hierárquicos dividem mesmo } \\
\text { ambiente de trabalho. }\end{array}$ & $\begin{array}{l}\text { - Modelo de gestão participativa, com } \\
\text { total liberdade de decisão para os } \\
\text { colaboradores. } \\
\text { - Liberdade de expressão. } \\
\text { - Adaptabilidade: redução de níveis } \\
\text { hierárquicos. } \\
\text { - Aumento da diversidade: os } \\
\text { colaboradores são estimulados a } \\
\text { contribuir com seu potencial criativo. } \\
\text { - Solução de conflitos de maneira local. }\end{array}$ \\
\hline Cooperação & $\begin{array}{l}\text { - Discussão das possíveis melhorias ou } \\
\text { possíveis soluções para problemas entre um } \\
\text { funcionário e seus pares. } \\
\text { - Cooperação entre funcionários de diferentes } \\
\text { setores na resolução de problemas de um dos } \\
\text { setores. }\end{array}$ & $\begin{array}{l}\text { - Colaboradores discutem entre si as } \\
\text { melhores soluções para os problemas e } \\
\text { oportunidades de melhoria. } \\
\text { - Colaboradores procuram atingir os } \\
\text { melhores resultados para a empresa. }\end{array}$ \\
\hline Agregação & $\begin{array}{l}\text { - Envolvimento de todas as pessoas } \\
\text { relacionadas a um processo na resolução de } \\
\text { problemas ou na busca por melhorias neste } \\
\text { processo. } \\
\text { - Defesa dos balizadores de cada setor por } \\
\text { parte de seus funcionários, mas não entrando } \\
\text { em conflito com os interesses da organização } \\
\text { como um todo. }\end{array}$ & $\begin{array}{l}\text { - Desenvolvimento de colaboradores } \\
\text { dentro da própria empresa, } \\
\text { sedimentando os valores da empresa em } \\
\text { cada colaborador. } \\
\text { - Envolvimento de todas as pessoas } \\
\text { relacionadas a um processo na resolução } \\
\text { de problemas ou na busca por melhorias } \\
\text { neste processo. }\end{array}$ \\
\hline Auto-organização & $\begin{array}{l}\text { - Acionamento de pontos de alavancagem por } \\
\text { parte do PCP. } \\
\text { - Processo dinâmico de melhoria contínua } \\
\text { consolidado no sistema produtivo da empresa. } \\
\text { - Sistema de feedback para os fornecedores. }\end{array}$ & $\begin{array}{l}\text { - Feedback aos colaboradores através de } \\
\text { avaliação } 360^{\circ} \text {. } \\
\text { - Acionamento de pontos de alavancagem } \\
\text { por parte do PCP. }\end{array}$ \\
\hline $\begin{array}{l}\text { Circuito duplo de } \\
\text { aprendizado }\end{array}$ & $\begin{array}{l}\text { - Busca dos motivos que levaram a um desvio } \\
\text { de rota no planejamento ou na programação } \\
\text { da produção. }\end{array}$ & - \\
\hline
\end{tabular}

Fonte: Autores, 2006. 
Cabe destacar aqui que os aspectos típicos de SCAs devem ser mais desenvolvidos nas empresas para que estas possam reagir às não-linearidades emergentes na operacionalização do PCP de maneira mais eficaz. A autonomia não pode ser concedida de maneira arbitrária. Ela depende da capacidade dos colaboradores em lidar com os problemas, assumindo responsabilidade por suas decisões diante da organização. Relaciona-se também com o tipo de controle requerido pelo processo de produção, sendo que onde há maior risco, deve haver controle mais rígido.

A cooperação vai depender da percepção de que existe uma relação ganha-ganha entre os colaboradores e a orga- nização. Para o desenvolvimento desta característica, uma comunicação clara é essencial.

A agregação e a auto-organização são decorrentes das duas primeiras características, e podem ser potencializadas pela sensação de pertinência à organização ou à seriedade com que são vistos pela mesma, fazendo parte de uma parceria duradoura, em que tanto o colaborador quanto a organização prosperarão.

\section{CONSIDERAC̣ÕES FINAIS}

O objetivo principal deste trabalho consistiu em verificar como as empresas vêm tratando as não-linearidades emer-

Quadro 3: Soluções para as não-linearidades incorporadas à prática do PCP.

\begin{tabular}{|c|c|c|}
\hline ETAPA DO PGP & NÃO-LINEARIDADE & SOLUÇÃO INCORPORADA AO PCP \\
\hline \multirow{3}{*}{$\begin{array}{l}\text { Planejamento da } \\
\text { Produção }\end{array}$} & $\begin{array}{l}\text { Divergências entre o projeto do } \\
\text { produto e o projeto do processo }\end{array}$ & $\begin{array}{l}\text { - Trabalhar o projeto do produto e do processo } \\
\text { de maneira integrada, seguindo os preceitos da } \\
\text { engenharia simultânea. } \\
\text { - Trabalhar com times de projeto interdepartamentais. }\end{array}$ \\
\hline & $\begin{array}{l}\text { Capacidade de produção } \\
\text { insuficiente para a demanda } \\
\text { existente }\end{array}$ & $\begin{array}{l}\text { - Considerar a capacidade de produção na fase de } \\
\text { projeto de um novo produto ou no horizonte de } \\
\text { planejamento de longo prazo. }\end{array}$ \\
\hline & $\begin{array}{l}\text { Entrega de produtos fora do } \\
\text { prazo estipulado pelo cliente }\end{array}$ & $\begin{array}{l}\text { - Trabalho sinérgico entre os setores comercial e de } \\
\text { produção para evitar atrasos ou para não vender } \\
\text { produtos além da capacidade de produção. } \\
\text { - Oferecer uma nova solução para o cliente, como } \\
\text { substituição por produtos similares em estoque. }\end{array}$ \\
\hline \multirow{6}{*}{$\begin{array}{l}\text { Programação e } \\
\text { controle da produção }\end{array}$} & $\begin{array}{l}\text { Reprogramação das quantidades } \\
\text { finais a produzir }\end{array}$ & $\begin{array}{l}\text { - Trabalhar com a construção de cenários futuros para } \\
\text { definir a melhor solução. }\end{array}$ \\
\hline & $\begin{array}{l}\text { Paradas na produção devido } \\
\text { a problemas de quebra de } \\
\text { máquinas e equipamentos }\end{array}$ & $\begin{array}{l}\text { - Considerar um intervalo de parada diária da produção } \\
\text { devido à quebra de máquinas e equipamentos, no } \\
\text { momento em que se realizar a programação. }\end{array}$ \\
\hline & $\begin{array}{l}\text { Atraso ou não conformidade no } \\
\text { fornecimento de insumos }\end{array}$ & $\begin{array}{l}\text { - Trabalhar com vários fornecedores. } \\
\text { - Criar mecanismos de feedback para os fornecedores. } \\
\text { - Trabalhar com certificação de fornecedores. }\end{array}$ \\
\hline & $\begin{array}{l}\text { Matéria-prima indisponível ou } \\
\text { fora das especificações no início } \\
\text { do processo produtivo }\end{array}$ & $\begin{array}{l}\text { - Trabalhar com uma margem de segurança nas ordens } \\
\text { de compra de matéria-prima. } \\
\text { - Automatizar o sistema de ordens de compra de } \\
\text { matéria-prima. }\end{array}$ \\
\hline & $\begin{array}{l}\text { Regra de seqüenciamento não } \\
\text { considera as prioridades de } \\
\text { produção }\end{array}$ & $\begin{array}{l}\text { - Realizar um ajuste fino da produção e estabelecer } \\
\text { regras de seqüenciamento que priorizem os produtos } \\
\text { já em carteira. } \\
\text { - Reprogramar produção de itens que estão sendo } \\
\text { produzidos para estoque. }\end{array}$ \\
\hline & $\begin{array}{l}\text { Desvios entre a produção } \\
\text { prevista e a produção realizada }\end{array}$ & $\begin{array}{l}\text { - Trabalhar com comunicação visual nas linhas de } \\
\text { produção para alavancar o comprometimento dos } \\
\text { funcionários com o cumprimento dos planos. }\end{array}$ \\
\hline
\end{tabular}

Fonte: Autores, 2006. 
gentes em seu PCP. Dentro do cenário de rápida mudança ao qual as organizações estão submetidas, vislumbrar os sistemas como sendo abertos e em constante interação com seu ambiente é crucial para um melhor entendimento das relações e interconexões que regem o funcionamento destes sistemas.

Sob o ponto de vista da Complexidade, as organizações podem ser vistas como um fenômeno que emerge da ação e da interação dos agentes componentes de um sistema. Vislumbrar os sistemas que compõem as organizações como SCAs permite buscar soluções para os problemas advindos da crescente complexidade em seu ambiente. desenvolvida uma metodologia de coleta e análise de dados, aplicada ao sistema de PCP de duas empresas. Tem-se a expectativa de que este trabalho possa auxiliar de alguma maneira outros trabalhos abordando o mesmo tema. A seguir, são apresentadas algumas recomendações para pesquisas futuras, baseadas nas limitações encontradas pelos pesquisadores para realizar o presente trabalho e também em percepções que os pesquisadores tiveram durante a realização do mesmo:

- Realização de pesquisas envolvendo os temas PCP e Complexidade com uma perspectiva longitudinal. Dada a complexidade existente em toda a cadeia produtiva de uma organização, a realização de uma pesquisa longitudinal, com uma duração de tempo maior e, preferencialmente, com a presença de pesquisadores in loco, vai gerar um trabalho com resultados robustos, contribuindo ainda mais para a sedimentação do tema. Uma

Abandona-se, desta maneira, a linearidade herdada do paradigma mecanicista, que enfatiza a subdivisão do sistema em suas partes, em favor de uma visão mais integrada. Nesta, a solução vem da dinâmica do sistema como um todo, e não da soma das ações isoladas das partes.

Ressalta-se que as empresas reconheceram que os principais entraves ao bom andamento do trabalho no sistema de PCP referem-se aos problemas não esperados que acontecem no dia-a-dia. Isto diz respeito às não-linearidades, 0 que mostra também a validade de se analisar o PCP através das lentes deste novo paradigma.

Deve-se salientar ainda que o caminho para a gestão autônoma de uma organização não é simples de se percorrer. Conforme destaca Agostinho (2003b), muitas vezes os administradores têm o receio de deixar o controle sair de suas mãos, o que é um obstáculo à auto-organização dos sistemas. Assim, os aspectos referentes aos SCAs podem ser mais desenvolvidos dentro das organizações, para que estas possam responder mais rapidamente às alterações que ocorrem em seu ambiente de operação.

Estudos referentes à Teoria da Complexidade são relativamente recentes, principalmente estudos empíricos aplicados a sistemas organizacionais. Neste trabalho foi pesquisa transversal com dois cortes também contribui neste sentido;

- Focar a pesquisa na etapa de controle do PCP. Por ser essa a etapa responsável por corrigir os desvios de rota do planejamento e da programação, estudos focando o controle vão gerar bons resultados de soluções para as não-linearidades emergentes no PCP;

- Apesar de o tema Complexidade ser relativamente novo, hoje em dia mais estudos envolvendo o assunto vêm sendo realizados. Desta forma, deve-se buscar na literatura outras abordagens, diferentes das utilizadas neste trabalho, envolvendo a Teoria da Complexidade;

- Realizar trabalhos quali-quantitativos envolvendo o tema. Uma sugestão é procurar mensurar em que nível de Complexidade os sistemas estudados se encontram.

Concluindo, este trabalho encerra uma abordagem para estudos do PCP visto como sendo um SCA. É importante enfatizar que não há um sistema de PCP considerado universal, mormente diante dos preceitos da Complexidade. Porém, abordagens sucessivas dentro desta ótica permitirão contribuir para o enriquecimento e "complexificação" da teoria em PCP e nortear trabalhos futuros. 


\section{Referências}

AGOSTINHO, M. C. E. Administração complexa: revendo as bases científicas da administração. RAE eletrônica, v. 2, n. 1, São Paulo, jan.jun. 2003a.

\section{Complexidade} organizações: em busca da gestão autônoma. São Paulo: Atlas, 2003b.

CORRÊA, H. L. et al. Planejamento, programação e controle da produção: MRP II/ ERP, conceitos, uso e implantação. São Paulo: Atlas, 1999.

DRUCKER, P. F. Administrando para futuro: os anos 90 e a virada do século. 5. ed. São Paulo: Pioneira, 1996.

ERDMANN, R. H. Administração do produção: planejamento, programação e controle. Florianópolis: Papa Livro, 2000 .

GODOY, A. S. Introdução à pesquisa qualitativa e suas possibilidades. Revisto de Administração de Empresas. São Paulo, v. 35, n. 3, mai./jun. 1995.
KLEMENT, C. F. F. Complexidade no sistema de produção de serviços: um estudo de caso no setor hoteleiro. Dissertação de Mestrado em Administração, CPGAUFSC. 2000

LEITE, M. S. A.; BORNIA. A. C.; COELHO C. C. S. R. Os conceitos de dialógica e sistema adaptativo complexo (SAC) aplicados à cadeia de suprimentos: uma contribuição da ciência da complexidade. Revista Pesquisa e Desenvolvimento Engenharia de Produção, n. 3, Itajubá, 2004

MONKS, J. G. Administração da produção. São Paulo: McGraw Hill, 1987.

MOREIRA, D. A. Administração da produção e operações. 2. ed. São Paulo: Pioneira, 1996.

MORGAN, G. Imagens da organização. São Paulo: Atlas, 1996.
MORIN, E. 0 método 1. A natureza da natureza. Portugal: Europa-América, 1977.

NOBREGA, C. Em busca da empresa quântica: analogias entre o mundo da ciência e o mundo dos negócios. Rio de Janeiro: Ediouro, 1996.

REBELO, L. M. B. A dinâmica do processo de formação de estratégias de gestão em universidades: a perspectiva da teoria da complexidade. Tese de Doutorado em Engenharia de Produção, PPGEPUFSC, 2004.

SHENK, D. Data smog: surviving the information glut. London: Abacus, 1997.

SLACK, N. et al. Administração da produção. São Paulo: Atlas, 1997.

STACEY, R. D. The Chaos Frontier: creative strategic control for business. Oxford: Butterworth-Heinemann, 1991.
SMITH, D.; ELLIOTT, D. Moving beyond denial: exploring the barriers to learning from crisis. Centre for Risk \& Crisis Management, 1999. Disponível em: http://www.shef.ac.uk/ mcn/6810/ reading/bjm-moving-beyond-denial. pdf\#search='Denis\%20Smith\%20and\%20 Dominic\%20Elliott'.

TÔRRES, J. J. M. Teoria da complexidade: uma nova visão de mundo para a estratégia. In: Encontro Brasileiro de Estudos da Complexidade, 1, 2005, Curitiba Anais do 1 EBEC.

VOSS, C.; TSIKRIKTSIS, N.; FROHLICH, $\mathrm{M}$. Case research in operations management. In: International Journal of Operations \& Production Management. Bradford, v. 22, n. 2, p. 195-219, 2002.

YIN, R. K. Estudo de caso: planejamento e métodos. 2. ed. Porto Alegre: Bookman, 2001

\section{- Sobre os autores}

Fernando Augusto Ferreira Dutra, Me.

Universidade Federal de Santa Catarina

End.: Avenida Pavão, 78, Apto. 22 - Moema - CEP 04516-010 - São Paulo - SP

Tel.: (11) 5041-5795 ou (11) 8119-1067

E-mail: ferdutra@gmail.com

Rolf Hermann Erdmann, Dr.

Universidade Federal de Santa Catarina - Centro Socioeconômico

End.: Caixa Postal 476 - Campus Universitário - Trindade - CEP 88040-900 - Florianópolis - SC

Tel.: (48) 3331-9365

Fax: (48) 3331-9539

E-mail: erdmann@.cse.ufsc.br 